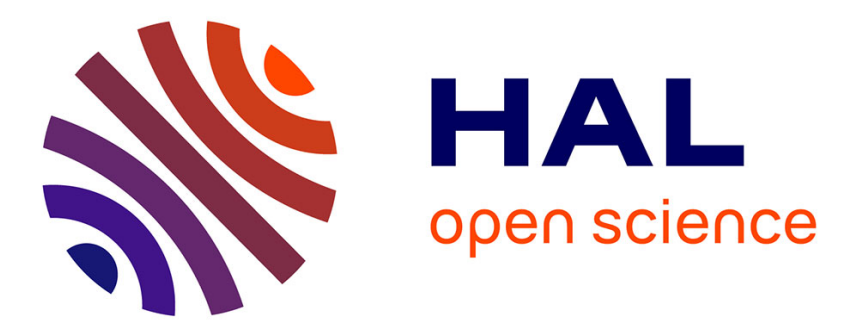

\title{
Cointrusive shear displacement by sill intrusion in a detachment: A numerical approach
}

Marie Chaput, Virginie Pinel, Vincent Famin, Laurent Michon, Jean-Luc Froger

\section{- To cite this version:}

Marie Chaput, Virginie Pinel, Vincent Famin, Laurent Michon, Jean-Luc Froger. Cointrusive shear displacement by sill intrusion in a detachment: A numerical approach. Geophysical Research Letters, 2014, 41 (6), pp.1937-1943. 10.1002/2013GL058813 . hal-01136471

\section{HAL Id: hal-01136471 https://hal.science/hal-01136471}

Submitted on 9 Oct 2017

HAL is a multi-disciplinary open access archive for the deposit and dissemination of scientific research documents, whether they are published or not. The documents may come from teaching and research institutions in France or abroad, or from public or private research centers.
L'archive ouverte pluridisciplinaire HAL, est destinée au dépôt et à la diffusion de documents scientifiques de niveau recherche, publiés ou non, émanant des établissements d'enseignement et de recherche français ou étrangers, des laboratoires publics ou privés. 


\section{Geophysical Research Letters}

\section{RESEARCH LETTER}

10.1002/2013GL058813

Key Points:

- We use numerical models to test the ability for sills to trigger flank sliding

- Overpressurized sills in a detachment produce large tangential displacements

- Coeruptive sliding at Piton de la

Fournaise may be explained by

sill intrusion

Correspondence to:

M. Chaput,

marie.chaput@univ-reunion.fr

\section{Citation:}

Chaput, M., V. Pinel, V. Famin, L. Michon, and J.-L. Froger (2014), Cointrusive shear displacement by sill intrusion in a detachment: A numerical approach, Geophys. Res. Lett., 41, 1937-1943, doi:10.1002/2013GL058813.

\section{Received 22 NOV 2013}

Accepted 2 MAR 2014

Accepted article online 6 MAR 2014

Published online 24 MAR 2013

\section{Cointrusive shear displacement by sill intrusion in a detachment: A numerical approach}

\author{
Marie Chaput ${ }^{1}$, Virginie Pinel ${ }^{2}$, Vincent Famin ${ }^{1}$, Laurent Michon ${ }^{1}$, and Jean-Luc Froger ${ }^{3}$ \\ ${ }^{1}$ Laboratoire GéoSciences Réunion, Université de La Réunion. Institut de Physique du Globe de Paris, UMR 7154, CNRS, \\ Sorbonne Paris Cité, Saint-Denis, France, ${ }^{2}$ ISTerre, Université de Savoie, IRD, CNRS, Le Bourget-du-Lac, France, ${ }^{3}$ Laboratoire \\ Magmas et Volcans UMR 6524, CNRS-IRD-Université Blaise Pascal, Clermont-Ferrand, France
}

Abstract Sheared sills are observed at Piton des Neiges (the eroded basaltic volcano of La Réunion) and are a suspected cause of the coeruptive flank displacement of Piton de la Fournaise in 2007. We performed a 2-D numerical study to quantify the perturbation induced by sill injection within a volcanic edifice. Magma is considered as an inviscid and pressurized fluid injected in an initially stable edifice under gravity-controlled extension. Two cases of injection are tested, in an elastic homogeneous edifice or along a detachment controlled by a friction law. We show that sill injection induces tangential displacements. This effect is strongly increased when sills are emplaced along a detachment, producing extension behind the injection and potentially ending in a large-scale flank collapse. Sill injections can thus explain the cointrusive shear deformation observed at Piton des Neiges and the tangential displacements measured at Piton de la Fournaise in 2007.

\section{Introduction}

Large flank landslides are common features in the long-lived evolution of volcanic edifices [McGuire, 1996]. Large-scale gradual horizontal displacements are also observed on several volcanoes, including Hawaii, [Brooks et al., 2008], Etna [Acocella and Puglisi, 2013], and Piton de la Fournaise [Brenguier et al., 2012]. These displacements, interpreted as flank sliding, are often linked to the eruptive activity, with undetected or slow displacement rates during quiescent periods and strong accelerations during eruptions [Brenguier et al., 2012; Cianetti et al., 2012]. Until recently, flank landslides and flank sliding have been addressed independently despite the frequent relationship between these phenomena [e.g., Iverson, 1995; Apuani et al., 2005a; Montgomery-Brown et al., 2010]. Stability studies are most often restricted to the question of flank failure initiation. They are not suitable to distinguish a large and rapid destabilization from a small-amplitude and slower flank sliding leading to stress readjustment toward a new state of equilibrium. Recent studies of Mount Etna have proposed numerical models aiming at constraining the interplay between gravity forces, magma ascent, and weakness zone in flank sliding. These models have emphasized the importance of the initial stress field in assessing the physical mechanisms expected to lead to flank instability [Cianetti et al., 2012; Apuani et al., 2013]. They also produce displacement fields to be compared to field measurements. Whatever the process, flank failure or flank sliding, most studies have focused on the ability of dike intrusion to trigger flank deformation [Elsworth and Voight, 1995; Cianetti et al., 2012]. However, structural data gathered at Piton des Neiges shield volcano have shown evidence for sliding associated with sill emplacement along a detachment [Famin and Michon, 2010] and this mechanism has recently been proposed as a potential cause of edifice weakening on Piton de la Fournaise [Got et al., 2013]. There is thus a need to quantify the ability of low-dipping magmatic intrusions to favor sliding. In this study, we investigate the effect of sill intrusion in a detachment, based on structural observations at Piton des Neiges [Famin and Michon, 2010; Chaput et al., 2014].

\section{Field Evidence of Sheared Sills Along a Detachment at Piton des Neiges}

Based on a stress inversion of faults, Chaput et al. [2014] showed that the stress field has been dominated by extension during the shield building stage of Piton des Neiges. The detachment, a low-angle normal fault, is located at the interface between a gabbroic body and debris avalanche deposits (Figure 1a). The plane is intruded by a stack of $50-70$ sheeted sills, with dips ranging between $20^{\circ}$ and $30^{\circ}$. This "sill zone" is exposed at two outcrops separated by a distance of $1.2-1.3 \mathrm{~km}$, providing a minimum length for the sills (Figure 1a). The emplacement depth of sills is estimated to range between 1.25 and $3.5 \mathrm{~km}$ at the shield building stage [Famin and Michon, 2010]. A third outcrop, below Piton des Neiges' summit, at $1.3 \mathrm{~km}$ above sea level (asl), exposes a 

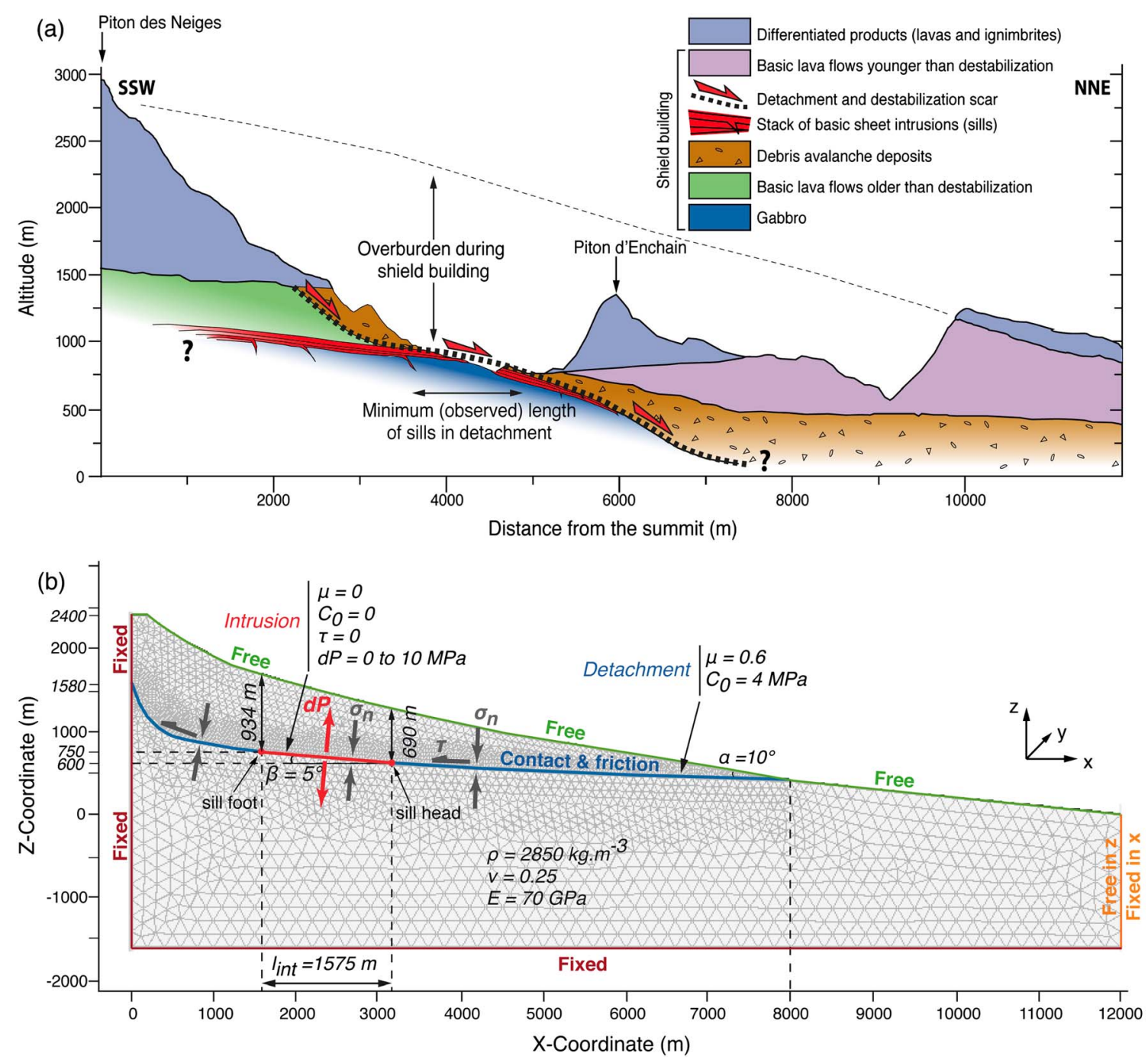

Figure 1. (a) Interpretative SSW-NNE cross section of Piton des Neiges used for the geometry of the model. (b) Meshed geometry, boundary conditions, and mechanical properties implemented in the model. See text for details.

normal-fault contact between basic lava flows and the debris avalanche deposit (Figure 1a), interpreted as the head scarp of a northward-directed (i.e., outward) landslide and as the upper subvertical part of the detachment. The detachment and the sill zone focus an intense north-verging ductile and brittle shear deformation, coeval with hydrothermal alteration. Mutual crosscutting among ductile and brittle kinematic markers indicates that both deformation styles alternated during the lifetime of the detachment. This dual deformation is interpreted as the consequence of rapid slip during sill intrusion and slow interintrusive shear deformation. Repeated slip events on the detachment may have triggered significant flank deformation, leading to a north-directed flank collapse of Piton des Neiges. Following this interpretation, we thus aim at testing and quantifying the ability for sills and inner weakness surfaces to generate flank instability on basaltic shields.

\section{Model and Method}

The model is built according to surface observations made at Piton de la Fournaise (volcano height and flank length) and to deep structural observations at Piton des Neiges (detachment geometry and sill length). Following Chaput et al. [2014], we consider that the edifice is loaded by gravity-driven extension. We model the edifice as two subdomains with a linear elastic rheology and similar mechanical properties, separated by 
a surface discontinuity. The sill is modeled as a pressurized inviscid fluid (i.e., shear stress is null) injected over a length of $1575 \mathrm{~m}$ along the discontinuity (Figure 1b). We use a 2-D Finite Element Modeling with the Structural Mechanics module of the COMSOL package to perform our computation. A 2-D plane strain approximation is adopted in our models, implying that deformation is null in the $y$ direction. Fixed boundary conditions are applied on the lower and leftside limits of the geometry. A "roller" condition is applied on the rightside frontier, which only allows displacements in the vertical $z$ direction. Finally, the upper boundary (i.e., the volcano flank) is considered as a free limit (Figure 1b). Two conditions have been tested: sill intrusion in a homogeneous edifice (Model 1) and along a detachment plane (Model 2). This allows quantifying how the perturbation induced by the sill injection is influenced by the presence of a detachment. The treatment of the detachment as a contact surface with a friction law introduces a strong non-linearity in the physical model. We thus perform an iterative procedure close to that of Cianetti et al. [2012] to obtain a non-deformed geometry under a condition of lithostatic equilibrium at the "initial state," before sill intrusion. In a preliminary step, the gravity load is implemented in the model. As the limit between the two subdomains is not yet considered as frictional, a physical continuity condition is applied on that boundary. The computed stress tensor is then exported and reinjected as an initial stress condition in a second step where an equilibrium stress state is reached, characterized by negligible displacements. The third step of the iterative procedure consists in simulating a detachment, by introducing a contact condition and a friction law on the limit between the two subdomains. Normal and tangential stresses estimated on this limit in the previous step are applied as initial values, and the friction law is set. The computed solution is then considered as the "initial state" for our model of sill intrusion (Figure 2a).

In the wide range of Young's moduli $(E)$ found in the literature for volcanic rocks at low confining pressures (1-100 GPa, [e.g., Schultz, 1995; Apuani et al., 2005b]), we chose a relatively large value of $E=70 \mathrm{GPa}$ to ensure numerical stability and to reduce the number of preliminary steps required in the computation of lithostatic equilibrium in presence of the detachment. For the other parameters of the elastic and friction laws, we used conventional values of Poisson's coefficient $(v=0.25)$, friction coefficient $(\mu=0.6)$, cohesion $\left(C_{0}=4 \mathrm{MPa}\right)$, and density $\left(\rho=2850 \mathrm{~kg} \cdot \mathrm{m}^{-3}\right)$ for basalts [Jaeger et al., 2007], in order to obtain negligible displacements (centimeter scale) at the initial state. Simulations were performed at magma overpressures of $0 \mathrm{MPa}$ (i.e., the sill is only a zero-friction surface), $4 \mathrm{MPa}$, and $8 \mathrm{MPa}$, in the range of values proposed in the literature [e.g., Gudmundsson et al., 1999; Fukushima et al., 2010].

\section{Results}

The results of simulations are presented in Figures 2 and 3. At the initial step (Figure 2a), the stress state is at the lithostatic equilibrium with $\sigma_{1}$ being subvertical, except in the few first hundred meters under the surface due to the topography. In the vicinity of the sill and detachment, topography effects become negligible. In the two models, variations of sill overpressures induce changes in the amplitude of displacements, not in the pattern of deformation. In Model 1, displacements are restricted to a zone between the intrusion and the surface of the edifice (Figure $2 \mathrm{~b}_{1}$ ). For an overpressure of $4 \mathrm{MPa}$, the maximum displacement amplitude is $28 \mathrm{~cm}$. The stress perturbation induced by the sill is reported in Figure $2 b_{2}$ as the difference in $\sigma_{3}$ magnitudes after and before sill intrusion, with negative stresses representing extension (geological convention). Two zones of traction $\left(\Delta \sigma_{3}=-20 \mathrm{MPa}\right)$ are created at the sill's foot and head due to intrusion opening. A diffuse traction is also observed from the sill's foot to the surface above the sill $\left(\Delta \sigma_{3}=-11 \mathrm{MPa}\right)$. In Model 2 , sill intrusion results in a larger zone of deformation, with displacements over $10 \mathrm{~cm}$ extending from $x=150$ to $5000 \mathrm{~m}$ above the detachment and with larger amplitudes of displacements between the sill and the surface (maximum $46 \mathrm{~cm}$, Figure $2 \mathrm{c}_{1}$ ). Displacement vectors clearly show that slip occurs on the detachment, along with opening in the sill area. At the flank surface, displacements are characterized by a dominant uplift above the sill but become mostly horizontal downhill (Figure $2 \mathrm{c}_{1}$ ). Stress perturbations are roughly similar to those of Model 1 except between the sill and the detachment's head where the slip on the detachment induces extension above the sliding plane. The traction is maximum for $x=0$ since the upper left boundary is fixed (Figure $2 c_{2}$ ).

We expressed the Coulomb's failure criterion (Figure 2d) to test the physical validity of the model and to check the equilibrium of the solution at the final step. For our model to be stable at the equilibrium, the criterion must not be verified, i.e., $|\tau|-\left(C_{0}+\mu \cdot \sigma_{n}\right)<0$, where $\tau$ is the tangential stress and $\sigma_{n}$ the normal stress (positive for compression). Figure $2 \mathrm{~d}$ shows that at the initial state, the detachment is stable and the 

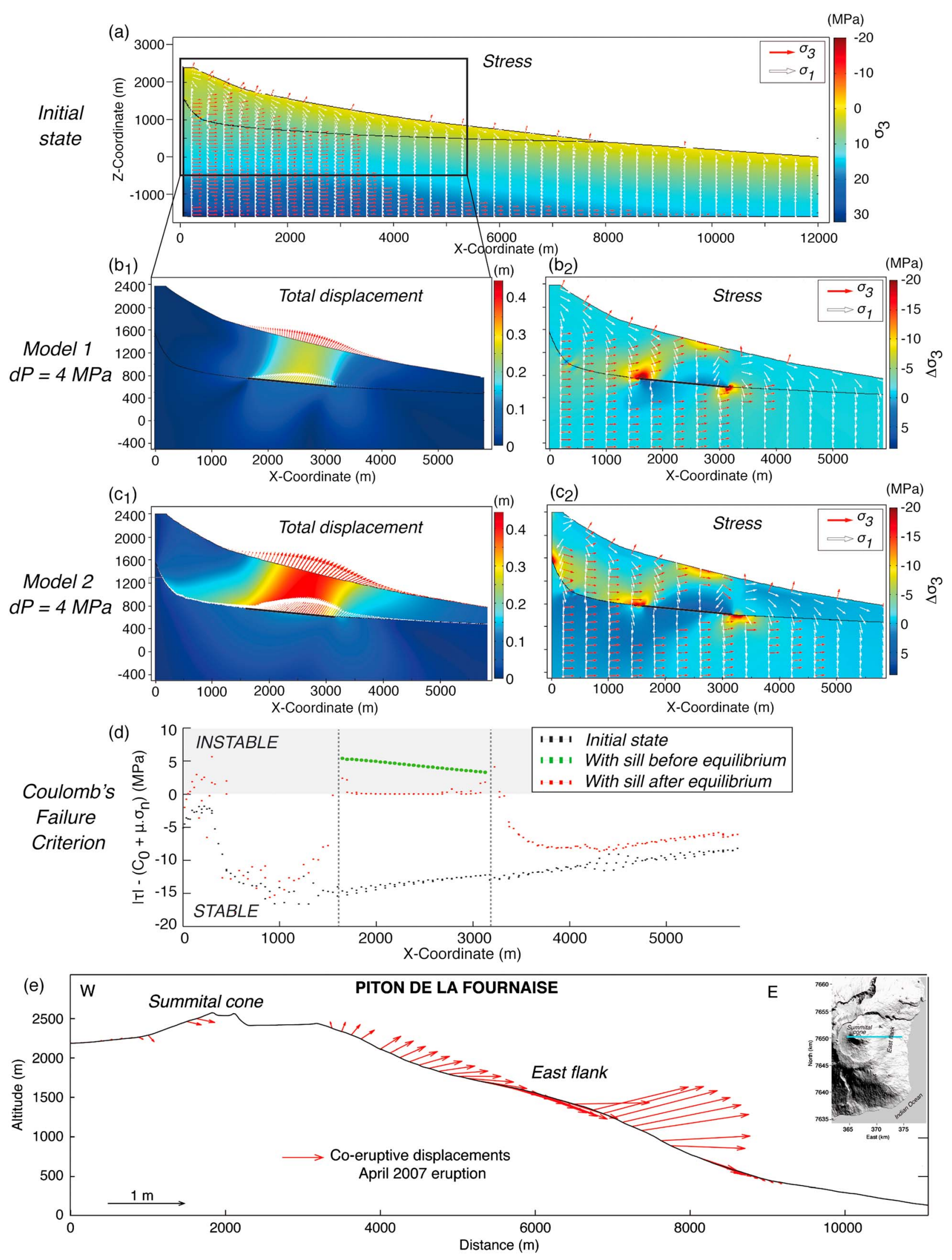

Figure 2 

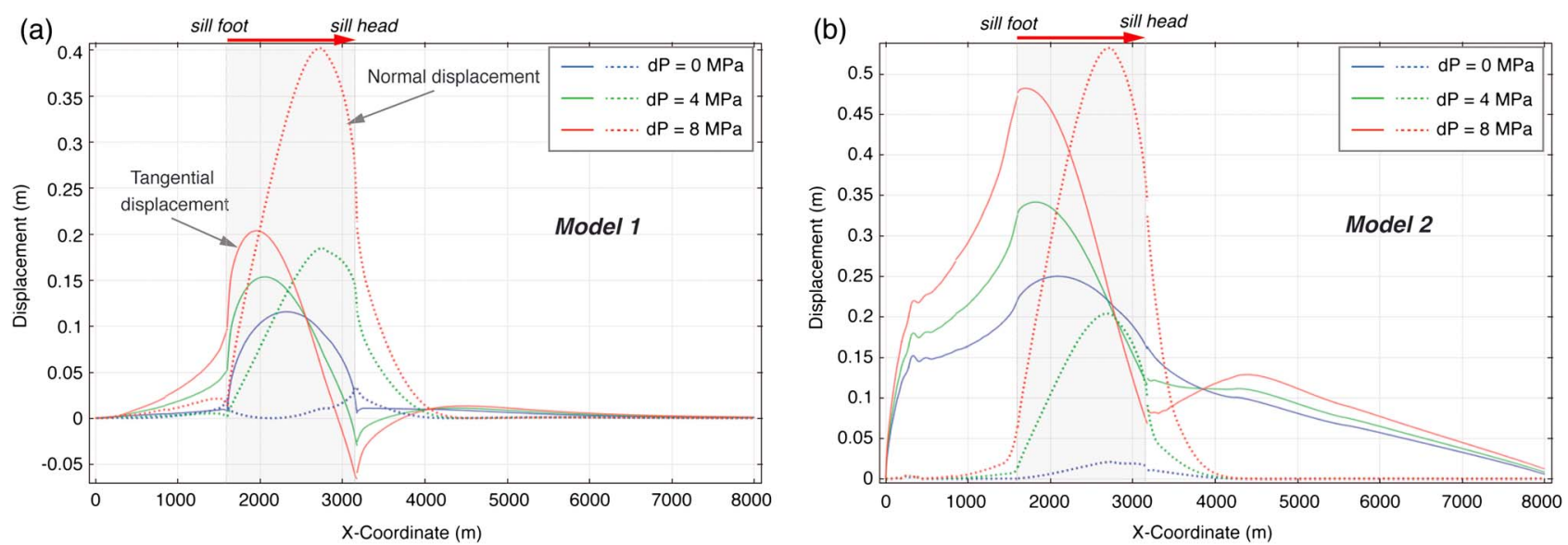

Figure 3. Tangential (solid lines) and normal (dotted lines) displacements on the detachment plane (upper surface) computed for sill overpressures of 0,4 , and $8 \mathrm{MPa}$ in (a) Model 1 and (b) Model 2.

solution is at equilibrium. Sill injection triggers a numerical disequilibrium, indicating a mechanical instability on the detachment. This transient condition evolves trough equilibrium at a stable stage, which is reached when sill emplacement is accommodated by a deformation of the edifice (and stress readjustments). Note that equilibrium is never reached when a free condition is applied on the upper medium left boundary to simulate a weak zone below the summit. This condition, which may simulate the effect of a hydrothermal system, makes the model physically instable.

What are the relative contributions of the sill and the detachment to the displacements? To answer this question, tangential (slip) and normal (opening) displacements occurring on the detachment surface have been computed for Models 1 and 2 (Figure 3). It is found that (1) a sill injection always triggers slip, yet slip is concentrated on the sill in Model 1 and affects the whole detachment in Model 2; (2) maximum slip occurs close to the sill's foot, whereas maximum opening occurs in the vicinity of the sill's head; and (3) the sill overpressure plays a significant role in the amplitude of slip: the greater the overpressure, the larger the slip on the detachment. Thus, flank sliding results of the combined influence of the absence of friction on the sill surface and its overpressure. The presence of a detachment significantly increases the amplitude of the lateral displacements due to the lower mechanical strength of the edifice and allows sliding on the entire discontinuity. The comparison between tangential displacements without and with a detachment suggests that the sill contributes to $40-45 \%$ of the maximum-recorded slip.

\section{Discussion}

At Piton des Neiges, several units of debris avalanche deposits have been reported on the emerged flanks, and some of them have a demonstrated offshore extent [e.g., Oehler et al., 2007]. Sills are the most abundant intrusions on this volcano [Chaput et al., 2014]. They are concentrated into piles of intrusions with seaward dips covered by debris avalanche deposits (Figure 1a). Field chronological markers suggest that these sills were intruded before and/or during the destabilizations. Our models demonstrate the ability for sills to produce flank sliding of the edifice and also suggest that sill intrusion in a detachment can trigger large flank landslides. We therefore propose that the sill zones observed at Piton des Neiges are responsible for the cointrusive shear deformation recorded at depth and have been a potential trigger of debris avalanches.

Figure 2. (a) Magnitude of $\sigma_{3}$ at the initial state (compression positive). Red and white arrows are the directions of $\sigma_{3}$ and $\sigma_{1}$, respectively. (b $\mathrm{b}_{1}$ ) Total displacement generated by sill intrusion in absence of detachment plane (Model 1; upper and lower medium are in continuity, and the interface is only a passive geometrical marker). Red and white arrows represent displacement vectors at the surface and on the sill, respectively. $\left(b_{2}\right)$ Stress perturbation plotted as the difference $\Delta \sigma_{3}$ between the final (after sill intrusion) and initial stages. $\left(c_{1}\right)$ Total displacement generated by a sill intruded in a detachment plane with a friction law. $\left(c_{2}\right)$ Stress perturbation after sill intrusion along the detachment. (d) Coulomb's failure criterion on the detachment for the initial step (black dots), for sill intrusion in the detachment before reaching equilibrium (transient step, green dots), and for sill intrusion in the detachment at the equilibrium (final step, red dots). (e) Surface displacement profile (red arrows) recorded by InSAR during the April 2007 lateral eruption (between 18 March and 30 April) represented on an east-west cross section of Piton de la Fournaise (La Réunion Island). Map coordinates in Universal Transverse Mercator (km) WGS84. 
At Piton de la Fournaise, unprecedented coeruptive displacements have been quantified by Interferometric Synthetic Aperture Radar (InSAR) during the April 2007 eruption [Froger et al., 2010]. On the eastern flank and between 2.2 and $0.5 \mathrm{~km}$ asl, up to $1.4 \mathrm{~m}$ of eastward displacement was recorded, together with a smaller-scale uplift up to $37 \mathrm{~cm}$ (Figure 2e). The overall displacement field suggests a large wavelength downslope sliding and a more localized uplift in the upper part of the moving flank. Large displacement gradients were also recorded at GPS stations on the eastern flank and may result from strain weakening of the edifice during the eruption [Got et al., 2013]. Our Model 2 provides a surface deformation pattern (dominant uplift upward and slip downward) in good agreement with most of the displacement field observed at Piton de la Fournaise. It is also consistent with the interpretations of Got et al. [2013] to explain edifice weakening during the eruption. On the contrary, Model 1 fails to explain the lateral displacements recorded outside the uplift area. The observed displacement profile is characterized by two areas of marked uplift: one at distance between 2.5 and $5 \mathrm{~km}$ and a more pronounced one at distance between 6.5 and $8 \mathrm{~km}$ (Figure 2e). This particular pattern and the large amplitude of displacements recorded at the flank bottom may be explained by a transient accumulation of magma under the surface, in agreement with the results of Vlastelic et al. [2013]. They are not reproduced by our models due to the oversimplified geometry considered for the magmatic intrusion. The differences in amplitude between our model and the recorded deformation may be explained by many factors, including the sill length, the overpressure and depth of the intrusion, the rheology of the medium, the initial stress state, or even a more complex internal structure of the edifice. An exhaustive inversion of the geodetic data exploring the space of parameters is beyond the scope of this paper. However, among the different parameters, our results raise the importance of taking into account both opening and slip on intrusion when inverting geodetic data. Given their resemblance with the surface deformation obtained in our models, the coeruptive uplift, the large wavelength eastward sliding, and the strain weakening recorded at Piton de la Fournaise during the April 2007 eruption could well be interpreted as due to a pressurized sill, emplaced under the eastern flank within a detachment. The existence of such weak plane under the east flank has been suggested by several authors [e.g., Merle and Lénat, 2003] and would be located 1 km deep, at the interface between a large intrusive complex and Piton de la Fournaise's lava flows [Rançon et al., 1989; Gailler et al., 2009]. Such structural organization, strikingly similar to that of the detachment exposed at Piton des Neiges, is highly consistent with the conclusions of our numerical models.

\section{Acknowledgments}

The authors thank the Editor Andrew Newman, Peter Cervelli and an anonymous reviewer for providing helpful comments. This is IPGP contribution 3508 .

The Editor thanks Peter Cervelli and an anonymous reviewer for assistance evaluating this manuscript.

\section{References}

Acocella, V., and G. Puglisi (2013), How to cope with volcano flank dynamics? A conceptual model behind possible scenarios for Mt. Etna, J. Volcanol. Geotherm. Res., 251, 137-148.

Apuani, T., C. Corazzato, A. Cancelli, and A. Tibaldi (2005a), Stability of a collapsing volcano (Stromboli, Italy): Limit equilibrium analysis and numerical modelling, J. Volcanol. Geotherm. Res., 144, 191-210, doi:10.1016/j.jvolgeores.2004.11.028.

Apuani, T., C. Corazzato, A. Cancelli, and A. Tibaldi (2005b), Physical and mechanical properties of rock masses at Stromboli: A dataset for volcano instability evaluation, Bull. Eng. Geol. Environ., 64(4), 419-431, doi:10.1007/s10064-005-0007-0.

Apuani, T., C. Corazzato, A. Merri, and A. Tibaldi (2013), Understanding Etna flank instability through numerical models, J. Volcanol. Geotherm. Res., 251, 112-126.

Brenguier, F., et al. (2012), First results from the UnderVolc high resolution seismic and GPS network deployed on Piton de La Fournaise Volcano, Seismol. Res. Lett., 83(1), 97-102.

Brooks, B. A., J. Foster, D. Sandwell, C. J. Wolfe, P. Okubo, M. Poland, and D. Myer (2008), Magmatically triggered slow slip at Kilauea Volcano, Hawaii, Science, 321, 1177.

Chaput, M., V. Famin, and L. Michon (2014), Deformation of basaltic shield volcano under cointrusive stress permutations, J. Geophys. Res. Solid Earth, 119, 274-301, doi:10.1002/2013JB010623.

Cianetti, S., C. Giunchi, and E. Casarotti (2012), Volcanic deformation and flank instability due to magmatic sources and frictional rheology: The case of Mount Etna, Geophys. J. Int., 191, 939-953, doi:10.1111/j.1365-246X.2012.05689.x.

Elsworth, D., and B. Voight (1995), Dike intrusion as a trigger for large earthquakes and the failure of volcano flanks, J. Geophys. Res., 100(B4), 6005-6024.

Famin, V., and L. Michon (2010), Volcanic destabilization by magma injections in a detachment, Geology, 38(3), 219-222, doi:10.1130/G30717.1.

Froger, J.-L., A. Augier, V. Cayol, and T. Souriot (2010), Some considerations about the April 2007 eruption at Piton de la Fournaise suggested by InSAR data, paper presented at 4th Collapse Caldera Workshop, IAVCEI, La Réunion Island, France.

Fukushima, Y., V. Cayol, P. Durand, and D. Massonnet (2010), Evolution of magma conduits during the 1998-2000 eruptions of Piton de la Fournaise volcano, Réunion Island, J. Geophys. Res., 115, B10204, doi:10.1029/2009jb007023.

Gailler, L. S., J.-F. Lénat, M. Lambert, G. Levieux, N. Villeneuve, and J.-L. Froger (2009), Gravity structure of Piton de la Fournaise volcano and inferred mass transfer during the 2007 crisis, J. Volcanol. Geotherm. Res., 184(1-2), 31-48, doi:10.1016/j.jvolgeores.2009.01.024.

Got, J.-L., A. Peltier, T. Staudacher, P. Kowalski, and P. Boissier (2013), Edifice strength and magma transfer modulation at Piton de la Fournaise volcano, J. Geophys. Res. Solid Earth, 118, 1-18, doi:10.1002/jgrb.50350.

Gudmundsson, A., L. B. Marinoni, and J. Marti (1999), Injection and arrest of dykes: Implications for volcanic hazards, J. Volcanol. Geotherm. Res., $88,1-13$.

Iverson, R. M. (1995), Can magma-injection and groundwater forces cause massive landslides on Hawaiian volcanoes, J. Volcanol. Geotherm. Res., 66(1-4), 295-308. 
Jaeger, J. C., N. G. Cook, and R. Zimmerman (2007), Fundamentals of Rock Mechanics, 4th ed., pp. 469, Blackwell, Malden, U.S.A. McGuire, W. J. (1996), Volcano instability: A review of contemporary themes, Geol. Soc. London Spec. Pub., 110(1), 1-23, doi:10.1144/gsl. sp.1996.110.01.01.

Merle, O., and J.-F. Lénat (2003), Hybrid collapse mechanism at Piton de la Fournaise volcano, Reunion Island, Indian Ocean, J. Geophys. Res., 108(B3), 2166, 1-11, doi:10.1029/2002JB002014.

Montgomery-Brown, E. K., D. K. Sinnett, M. Poland, P. Segall, T. Orr, H. Zebker, and A. Miklius (2010), Geodetic evidence for en echelon dike emplacement and concurrent slow slip during the June 2007 intrusion and eruption at Kilauea volcano, Hawaii, J. Geophys. Res., 115, B07405, doi:10.1029/2009jb006658.

Oehler, J.F., J.-F. Lénat, and P. Labazuy (2007), Growth and collapse of the Reunion Island volcanoes, Bull. Volcanol., 70(6), 717-742, doi:10.1007/s00445-007-0163-0.

Rançon, J.P., P. Lerebour, and T. Augé (1989), The Grand Brulé exploration drilling: New data on the deep Framework of Piton de la Fournaise volcano. Part 1: Lithostratigraphic units and volcanostructural implications, J. Volcanol. Geotherm. Res., 36(1-3), 113-127.

Schultz, R. A. (1995), Limits on strength and deformation properties of jointed basaltic rock masses, Rock Mech. Rock Eng., 28(1), 1-15. Vlastelic, I., G. Menard, A. Gannoun, J.-L. Piro, T. Staudacher, and V. Famin (2013), Magma degassing during the April 2007 collapse of Piton de la Fournaise: The record of semi-volatile trace elements (Li, B, Cu, In, Sn, Cd, Re, Tl, Bi), J. Volcanol. Geotherm. Res., 254, 94-107. 